\title{
T cell derived HB-EGF prevents Th17 cell differentiation in an autocrine way.
}

Felicity Macdonald ${ }^{1}$, Jorg van Loosdregt ${ }^{2}$, Dietmar M W Zaiss ${ }^{1}$

${ }^{1}$ Institute of Immunology and Infection Research, School of Biological Sciences, University of Edinburgh, Edinburgh EH9 3FL, UK.

${ }^{2}$ Centre for Translational Immunology, University Medical Centre Utrecht, Utrecht, The Netherlands

Correspondence should be addressed to Dietmar.Zaiss@ed.ac.uk

\section{SUMMARY}

CD4 T cell activation induces the expression of the EGFR and its high-affinity ligand HB-EGF. HB-EGF sustains IL-2 expression in an autocrine manner, preventing the differentiation of Th17 cells and the subsequent induction of Th17 cell-mediated autoimmune diseases. 


\section{ABSTRACT}

CD4 T cells critically contribute to host immunity against infections, but can also contribute to the development of autoimmune diseases. The underlying mechanisms that govern differentiation of naïve CD4 T cells into different effector populations remain poorly understood. Here, we show that the expression of the Epidermal Growth Factor (EGF)-like growth factor HB-EGF by CD4 T cells sustained their expression of Interleukin (IL)-2 and reduced their capacity to differentiate into T Helper 17 (Th17) cells. Concordantly, mice with a $T$ cell specific deficiency of HB-EGF showed an enhanced differentiation of naïve CD4 T cells into Th17 cells and a more rapid onset of experimental autoimmune encephalomyelitis $(E A E)$. Furthermore, transfer of naïve HB-EGF-deficient CD4 T cells into Rag $1^{\text {-1- }}$ mice led to the rapid induction of multi-organ inflammation in recipient mice. Together, our data reveal a novel mechanism by which an HB-EGF-mediated constrain on Th17 differentiation prevents the development of autoimmune diseases. 


\section{INTRODUCTION}

CD4 T cells are key regulators of immune responses. Cytokines produced by CD4 T cells during pathogen-specific responses are critical effector molecules that regulate the local immune response and pathogen clearance. For instance, IFNy-producing Th1 cells directly contribute to the clearance of Leishmania or Mycobacterium leprae (Modlin, 1994), IL-17producing Th17 cells contribute to fungal resistance (Conti et al., 2009), and IL-13-producing Th2 cells contribute to the clearance of helminths (Else et al., 1994; Minutti et al., 2017). Deficiencies in $\mathrm{T}$ cell differentiation can result in enhanced pathogen load and immune pathology. In addition, T cells can contribute to the development of autoimmune diseases and the differentiation of naïve CD4 T cells into pro-inflammatory Th17 cells has been shown to be a critical step in the development of autoimmune diseases (Annunziato et al., 2009; Ivanov et al., 2006). Therefore, the correct differentiation of CD4 effector populations is a fundamental step in the regulation of immune responses. Nevertheless, the precise mechanisms that direct in vivo CD4 T cell differentiation has remained poorly understood.

We and others have shown that Epidermal Growth Factor Receptor (EGFR) expression is essential for efficient regulatory $\mathrm{T}$ cell (Treg) and effector CD4 T cell function and therefore critically contributes to immune regulation (Zaiss et al., 2013), host defense (Minutti et al., 2017) and the development of immune mediated diseases, such as atherosclerosis (Zeboudj et al., 2018). Nevertheless, whether EGFR expression by CD4 T cells may also influence their differentiation into different effector types, has remained unresolved so far.

The EGFR is an evolutionary conserved transmembrane receptor known to play a critical role in tissue development and cancer formation (Sibilia et al., 2007). The EGFR is also widely expressed by leukocytes, such as macrophages (Hardbower et al., 2016; Lanaya et al., 2014) and plasma cells (Mahtouk et al., 2005), and is a critical regulator of stress-induced expression of NKG2D ligands such as MICA/B, which govern the local initiation of immune responses by activating NK-cells (Vantourout et al., 2014). Furthermore, human and mouse CD4 T cells express the EGFR upon activation (Minutti et al., 2017; Zaiss et al., 2013; Zeboudj et al., 2018). The EGFR has been shown to be one of the most upregulated genes upon STAT-5 signalling in mouse CD4 T cells (Beier et al., 2012; Liao et al., 2008) and, in human Tregs, the EGFR was found to be the single most upregulated transmembrane kinase upon activation (Tuettenberg et al., 2016).

Similar to the EGFR, the high-affinity EGFR ligand Heparin-Binding EGF-like Growth Factor (HB-EGF) has been shown to be expressed on newly-activated naïve CD4 T cells (Blotnick et al., 1994). HB-EGF binding leads to the autophosphorylation of the EGFR, ensuing MAPkinase (MAPK) and STAT-5 signalling pathway activation (Heo et al., 2018). Both signal 
transduction pathways are crucial for the differentiation of CD4 T cells. In addition, upon endocytosis induced by the binding of high-affinity ligands, EGFR activity is closely regulated by the phosphate PTPN-2 (Stanoev et al., 2018). Since individuals with dysfunctional PTPN2 expression are strongly predisposed to the development of auto-immune diseases, and as this phosphate is highly expressed in T cells (Doody et al., 2009), we decided to test whether EGFR mediated signalling and the expression of its ligands by CD4 T cells may influence the differentiation of CD4 T cells into their different subpopulations and in this way may contribute to the development of autoimmune diseases.

Here, we describe the finding that the high-affinity EGFR ligand HB-EGF blocks Th17 differentiation in an autocrine manner and that both in vitro and in vivo HB-EGF-deficient CD4 $\mathrm{T}$ cells differentiated more readily into Th17 cells. Upon transfer into Rag $1^{-/}$mice, recipients of naïve HB-EGF-deficient CD4 T cells developed unanticipated early-onset of wasting disease and multi-organ inflammation, which also affected the central nervous system. Mechanistically, we found that CD4 T cells deficient in HB-EGF express lower levels of IL-2 upon activation and showed diminished STAT-5 signalling. As STAT-5 signalling has been shown to interfere with Th17 differentiation (Laurence et al., 2007), these findings suggest a novel mechanism by which HB-EGF-mediated signalling in naïve CD4 T cells forms a threshold preventing their aberrant differentiation into Th17 cells, thereby limiting the development of autoimmune diseases. 


\section{RESULTS}

\section{Unaltered T cell compartment in mice with T cell-specific HB-EGF deficiency at steady state}

HB-EGF has been described to be expressed by CD4 T cells following activation (Blotnick et al., 1994). To confirm these findings in CD4 T cells derived from C57BL/6 mice, we activated naïve CD4 T cells either using a-CD3/a-CD28 coated beads or naïve CD4 T cells from from a TCR transgenic mouse line in peptide-specific way. We detected a dose-dependent expression of HB-EGF on activated CD4 T cells (Figure 1A \& B). We have shown before that EGFR expression by CD4 T cells can be sustained by STAT- 5 inducing cytokines, but initially requires an induction of expression via the TCR (Minutti et al., 2017). Remarkably, in the case of HB-EGF deficient CD4 T-cells we found that induced HB-EGF expression was essential for the induction of EGFR expression (Figure 1C). Based on these data, we concluded that an HB-EGF mediated feed-back loop is essential for the induction of appreciable levels of EGFR expression on newly activated CD4 T cells.

In order to evaluate the function of T cell-expressed HB-EGF, we established mice with a T cell-specific deficiency in HB-EGF (CD4:cre $x \mathrm{Hbegf}^{f / f l}$, from now on called CD4 ${ }^{\triangle \mathrm{HB}-\mathrm{EGF}}$ ). To ascertain the activation states of $\mathrm{T}$ cells in these mice at steady state, we analysed $\mathrm{T}$ cells derived from spleen, inguinal lymph nodes (iLN), intraepithelial lymphocytes (IEL) and the lamina propria (LP) of the small intestine for CD44 and CD62L expression. As shown in Figure $\mathrm{S} 1$, we saw no difference in number and percentage of naïve $\mathrm{CD}^{+} \mathrm{T}$ cells $\left(\mathrm{CD} 62 \mathrm{~L}^{+} \mathrm{CD}^{-} 4^{-}\right)$, effector $\mathrm{CD}^{+} \mathrm{T}$ cells $\left(\mathrm{CD} 62 \mathrm{~L}^{-} \mathrm{CD} 44^{+}\right)$or central memory $\mathrm{CD} 4^{+} \mathrm{T}$ cells $\left(\mathrm{CD} 62 \mathrm{~L}^{+} \mathrm{CD}_{4} 4^{+}\right)$ compared to wild type (wt) C57BL/6 mice and mice with a T cell-specific deficiency in EGFR expression (Cd4:cre $x$ Egfr ${ }^{f / / f l}$, from now on called CD4 ${ }^{\triangle E G F R}$ ).

These data suggest that neither a T cell specific lack of HB-EGF or of EGFR expression influences the thymic maturation of $\mathrm{T}$ cell subpopulations or induce the development of spontaneous autoimmune diseases at steady state. Therefore, we concluded that similar to our finding in CD4 ${ }^{\triangle E G F R}$ mice (Minutti et al., 2017), T cell-specific HB-EGF deficiency does not play a major role in $\mathrm{T}$ cell development and homeostasis.

\section{Rapidly expansion of Th17 cell populations in CD4 ${ }^{\triangle \mathrm{HB}-\mathrm{EGF}}$ mice}

To assess the influence of T cell-derived HB-EGF on in vivo CD4 T cell differentiation, we injected activating $\alpha \mathrm{CD} 3$ antibodies into wt C57BL/6 and CD4 ${ }^{\triangle \mathrm{HB}-\mathrm{EGF}}$ mice. It has previously been reported that $\alpha C D 3$ antibody injection induces activation-induced T cell death, along with a systemic upregulation of IL- 6 and TGF $\beta$. This induces the de novo differentiation of Th17 cells, their recruitment to the small intestine and local inflammation in the small intestine 
(Esplugues et al., 2011). As shown in Figures 2, we found that 48 hours following injection of $\alpha \mathrm{CD} 3$ antibodies into wt C57BL/6 and CD4 ${ }^{\triangle \mathrm{HB}-\mathrm{EGF}}$ mice the proportion of $\mathrm{IL}-17^{+}$, ROR $\mathrm{Rt}^{+}$and $\mathrm{IL}-17^{+} \mathrm{ROR} \gamma \mathrm{t}^{+}$double-positive IELs in CD4 ${ }^{\triangle \mathrm{HB}-\mathrm{EGF}}$ mice was significantly increased compared to wt counterparts.

These data suggest that a deficiency of HB-EGF expression by CD4 T cells enhances the in vivo differentiation of Th17 cells.

\section{HB-EGF suppresses Th17 cell differentiation in vitro}

To determine whether HB-EGF-deficient CD4 T cells retain the same capacity as wt cells to differentiate into different effector populations, we sorted naïve CD4 T cells from C57BL/6 wt, CD4 ${ }^{\triangle \mathrm{EGFR}}$ and $\mathrm{CD} 4^{\triangle \mathrm{HB}-\mathrm{EGF}}$ mice and polarised these cells in vitro. As shown in Figure 3, we found that similar to Th2 cells (Minutti et al., 2017) also Th1 and induced Treg (iTreg) differentiation does not appear to be substantially influenced by a lack of HB-EGF or EGFR expression. However, we detected enhanced Th17 cell differentiation with both EGFR and HB-EGF deficiency when staining for the Th17 master transcription factor ROR $\gamma$ (Figure 3A). In the presence of recombinant IL-6 and TGF $\beta$, a significantly higher percentage of CD4 T cells derived from CD4 $4^{\triangle \mathrm{EGFR}}$ and CD4 ${ }^{\triangle \mathrm{HB} \text {-EGF }}$ mice differentiated into Roryt-expressing Th17 cells compared to CD4 T cells derived from wt C57BL/6 mice (Figure 3A). This increased potential to differentiate into Th17 cells was reversed in a dose-dependent manner upon the addition of recombinant HB-EGF to the polarisation culture media of CD4 T cells derived from CD4 ${ }^{\triangle \mathrm{HB}-\mathrm{EGF}}$ mice, but not in those derived from CD4 ${ }^{\triangle \mathrm{EGFR}}$ mice (Figure 3D). These data suggest that HB-EGF constrains the differentiation of naïve CD4 T cells into Th17 cells by signalling through the EGFR.

To assess whether human CD4 T cells respond to HB-EGF in a similar fashion, PBMCs were obtained from healthy donor blood and CD4 T cells were isolated. Cells were bulk transfected with recombinant CRISPR/Cas9 and guide RNA specific for Hbegf or Egfr gene sequences or a scrambled control guide RNA. After resting for two days, cells were in vitro polarised towards a Th17 phenotype. While we only found a partial reduction in HB-EGF expression in CRISPR/Cas9 treated cells by Western blot of bulk treated cells, we consistently found a significantly higher percentage of Roryt ${ }^{+}$Th17 cells in CD4 T cell populations treated with Hbegf or Egfr gene-specific guide RNA than in unstimulated CD4 T cells or CD4 T cells which underwent editing using a scrambled guide RNA (Figures S2A \& B). These findings suggest that in vitro HB-EGF-mediated signalling has a similar ability to diminish Th17 cell differentiation in both mouse and human CD4 T cells. 


\section{HB-EGF enhances IL-2 expression in activated CD4 T cells}

In order to better understand the mechanism by which HB-EGF-mediated signalling diminished Th17 cell differentiation, we measured the production of IL-2 by activated CD4 T cells. We have shown previously that EGFR-deficient CD4 T cells initially show inferior proliferation upon activation compared to their wt counterparts (Minutti et al., 2017). Activated CD4 T cells require autocrine IL-2 to aid in clonal expansion, and the proliferation deficiency of EGFR-deficient CD4 T cells could be overcome by the supplementation of culture media with recombinant IL-2 in a dose dependent manner (Minutti et al., 2017).

To investigate the influence of T cell derived HB-EGF on IL-2 expression, we activated naïve CD4 T cells in vitro and measured proliferation along with IL-2 production over the following 24-48 hours. We found that in the presence of recombinant IL-2, proliferation of T cells derived from CD4 ${ }^{\triangle \mathrm{HB}-\mathrm{EGF}}$ or C57BL/6 wt mice was comparable (Figure 4A). However, both HB-EGFand EGFR-deficient CD4 T cells produced significantly less IL-2 than wt cells upon activation (Figure 4B). In line with these findings, the activation-induced upregulation of the IL-2 receptor, CD25, was significantly diminished, as was the activation of the STAT-5 signalling pathways, in HB-EGF- and EGFR-deficient CD4 T cells (Figure 4C \& D).

To further explore the proliferative capacity of HB-EGF-deficient T cells in vivo, we utilised the Rag $^{-/-}$transfer model, in which intravenously injected naïve CD4 T cells undergo lymphopenia-induced proliferation and activation (Bourgeois et al., 2005). Upon injection of a

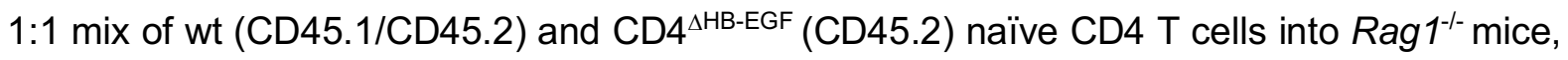
we observed a dramatically diminished recovery of HB-EGF-deficient cells in comparison to wt CD4 T cells on day 5 post transfer, with the majority of retrieved donor cells coming from the transferred wt $T$ cell population (Figure 4E).

These data illustrate that HB-EGF-mediated signalling sustains CD4 T cell expansion in an autocrine manner, potentially by enhancing the production of IL-2 by activated CD4 T cells.

\section{Transfer of naive HB-EGF-deficient CD4 T cells into Rag $1^{-/}$mice induces their rapid differentiation into Th17 cells}

IL-2-induced STAT-5 signalling has been shown before to interfere with Th17 cell differentiation (Laurence et al., 2007). Therefore, our finding that HB-EGF-deficient CD4 T cells express diminished levels of IL-2 may account for the observed enhanced in vitro differentiation into Th17 cells. To further assess the capacity of naïve HB-EGF-deficient CD4 T cells to differentiate into Th17 cells in vivo, we followed the transferred 1:1 mix of wt (CD45.1) and HB-EGF-deficient (CD45.2) T cells in Rag 1/-- mice for an extended period of time. As time progressed, we found that the transferred HB-EGF-deficient $T$ cell population recovered until there was an equal ratio of CD45. $1^{+}$wt to CD45.2 $2^{+}$HB-EGF-deficient donor CD4 T cells 
(Figure 5A). Furthermore, when the transferred populations were assessed for effector cell differentiation, we found that from day 14 post-transfer onwards there was a significantly stronger polarisation of IL-17 and IFN $\gamma$ co-secreting Th17 cells within the CD45.2 ${ }^{+} \mathrm{HB}-\mathrm{EGF}-$ deficient $T$ cell population compared to the $C D 45.1^{+}$wt $T$ cell population (Figure $5 B$ ), demonstrating that in vivo CD4 ${ }^{\triangle \mathrm{HB}-\mathrm{EGF}}$ cells differentiated more readily into Th17 cells than their co-transferred wt counterparts.

These data further support the proposition that T cell-derived HB-EGF counteracts the differentiation of naïve CD4 T cells into Th17 cells in an autocrine manner.

\section{Transfer of naive HB-EGF-deficient CD4 T cells into Rag ${ }^{/ /}$mice induces the rapid onset of multi-organ inflammation and wasting disease}

Transfer of naïve CD4 T cells into lymphopenic mice is a well-established model for the induction of colitis (Powrie et al., 1994). For colitis induction, transferred T cells have first to differentiate into Th17 cells before they migrate in a CXCR6-dependent manner into the colon, where they then differentiate into IFN $\gamma^{+}$Th1/Th17-like cells and cause colitis (Harbour et al., 2015). The transfer of fully differentiated Th17 cells into lymphopenic mice causes a rapid onset of disease (Lee et al., 2009). Therefore, to assess the capacity of HB-EGF-deficient T cells to induce colitis, we transferred naïve CD4 T cells derived from either C57BL/6 wt or CD4 ${ }^{\triangle \mathrm{HB} \text {-EGF }}$ mice into Rag $1^{-/-}$mice. The injection of naïve wt CD4 T cells induced the expected progression of disease in recipient Rag $1^{-/}$mice, with weight loss being initiated at around 6 weeks after transfer (Harbour et al., 2015). However, the transfer of naïve HB-EGF-deficient CD4 $\mathrm{T}$ cells induced an unexpected, rapid onset of wasting disease at around 3 weeks post transfer (Figure $5 \mathrm{C}$ ). The disease was characterized by multi-organ inflammation, which was especially pronounced in the small and large intestine (Figure 5D). However, in these mice we occasionally also observed the onset of atypical EAE (constant turning of individuals due to a loss of balance) as well as conventional EAE (full paralysis of tail and hind legs). To test whether TGF $\beta$-mediated differentiation of transferred $T$ cells into Th17 cells might be contributing to the early onset of disease in recipient mice, we injected TGF $\beta$ blocking antibodies (1D11) into Rag $1^{-/-}$mice that had received naïve CD4 T cells from CD4 ${ }^{\triangle \mathrm{HB}-\mathrm{EGF}}$ mice. Injection of TGF $\beta$ blocking antibodies prevented the early onset of disease (Figure S3A), suggesting that TGF $\beta$ mediated differentiation into Th17 cells contributes to the early onset of disease. As we did not detect a difference in the differentiation of transferred naïve CD4 T cells into iTregs between the mouse groups (Figure S3B), we propose that the rapid differentiation of HB-EGF-deficient CD4 T cells into Th17 cells might be the most likely reason for the early onset of disease. 


\section{CD4 ${ }^{\triangle \mathrm{HB}-\mathrm{EGF}}$ mice show earlier onset of EAE symptoms}

To further explore whether the enhanced Th17 cell differentiation caused by HB-EGF deficiency impacts on the development of Th17 cell-driven autoimmune diseases, we induced experimental autoimmune encephalomyelitis (EAE) in C57BL/6 wt and CD4 $4^{\triangle \mathrm{HB}-\mathrm{EGF}}$ mice. In this classical mouse model of multiple sclerosis, myelin oligodendrocyte glycoprotein (MOG)specific Th17 cells differentiate in primary and secondary lymph nodes before entering the CNS, leading to subsequent demyelination of nerves (Hirota et al., 2011). As shown in Figure 6 , we found that CD4 ${ }^{\triangle \mathrm{HB}-\mathrm{EGF}}$ mice exhibited a significantly higher frequency of IL-17 expressing $\mathrm{T}$ cells following $\mathrm{CFA} / \mathrm{MOG}_{35-55}$ immunization (Figure $6 \mathrm{~A}$ ) and, in comparison to their wt littermates, CD4 ${ }^{\triangle H B-E G F}$ mice exhibited an earlier onset of symptoms (Figure $6 B \& C$ ).

Together, these findings indicate that CD4 T cell-derived HB-EGF lessens the differentiation of Th17 cells in an autocrine manner, and therefore prevents the induction of Th17-mediated inflammatory and autoimmune diseases. 


\section{DISCUSSION}

Our data reveal a novel mechanism by which $\mathrm{T}$ cell-derived HB-EGF constrains Th17 differentiation in an autocrine manner and thereby prevents the development of autoimmune diseases. Mechanistically, we found that T cell-derived HB-EGF induces the enhanced expression of IL-2 by CD4 T cells. IL-2 is a critical T cell survival factor. Furthermore, IL-2 induced STAT-5 signalling blocks the expression of the master Th17 transcription factor Ror $\gamma \mathrm{t}$ (Laurence et al., 2007) and inhibits IL-6 receptor expression, a key cytokine signalling pathway required for the differentiation of Th17 cells (Yang et al., 2011). Nevertheless, the exact molecular mechanism by which HB-EGF diminishes Th17 differentiation remains to be addressed. It is conspicuous that of all EGFR ligands only HB-EGF has been described to induce EGFR-mediated activation of STAT-5 (Heo et al., 2018). Thus, it is tempting to speculate that HB-EGF mediated signalling may also directly sustain STAT-5 activation. In such a way, HB-EGF may in parallel to enhanced IL-2 expression also directly counterbalance IL-6 / TGF $\beta$ mediated ROR $\gamma$ t expression and consequently Th17 differentiation. Thus, the exact contribution of the different mechanisms by which T cell-derived HB-EGF interferes with Th17 differentiation remain to be dissected in future studies.

Nonetheless, it is striking to establish a role of the EGFR in Th17 differentiation. Recently, it has been shown that the Insulin-like Growth Factor Receptor (IGFR), a transmembrane Receptor Tyrosine Kinase (RTK) closely related to the EGFR, is also expressed on activated CD4 T cells (DiToro et al., 2020). Long-term expression is retained specifically on Th17 effector cells and Tregs (DiToro et al., 2020). IGFR has been found to promote Th17 cell differentiation through activation of PLC, PKB/AKT and mTOR signalling. Conversely, our data show that HB-EGF signalling through the EGFR diminishes Th17 cell differentiation. Remarkably, the EGFR is one of the most down-regulated genes in Th17 cells differentiated in the presence of IGF (DiToro et al., 2020), suggesting that there is an antagonistic regulation of Th17 cell differentiation between the IGFR and the EGFR. As both the IGFR and EGFR are expressed on newly-activated CD4 T cells, the expression of ligands such as HB-EGF or IGF1/2 may antagonistically modulate Th17 cell differentiation.

In line with such an assumption, it has been shown previously that low strength activation of human CD4 T cells in vitro promotes the differentiation of cells into Th17 effector cells (Purvis et al., 2010). Our data show a direct correlation between $T$ cell activation and HB-EGF expression. Thus, potentially a diminished HB-EGF expression might contribute to the described enhanced differentiation of low strength activated CD4 T cells into Th17 effector 
cells. Furthermore, in many infections, immunodominant $\mathrm{T}$ cell clones often express TCRs with a high affinity for their cognate antigens. Based on our data, we would assume that clones expressing low-affinity TCRs for their cognate antigen will induce a lower expression of HBEGF than those expressing high-affinity TCRs. Such a correlation may then suggest a mechanism whereby strong TCR activation leads to sustained HB-EGF mediated IL-2 signalling and may thus favour the clonal expansion of immunodominant $T$ cell clones. Conversely, T cell clones with a TCR showing a low affinity for self-antigen may escape central tolerance during thymic selection. Upon low-affinity antigen binding such $T$ cells may then express minimal amounts of HB-EGF and may therefore more readily differentiate into pathogenic Th17 cells, thereby supporting the development of autoimmune diseases. Addressing such a hypothesis may require substantially more work. Nonetheless, it is striking to observe that the phenotype of HB-EGF-deficient CD4 T cells closely resembles those with a deficiency in PTPN-2 expression (Spalinger et al., 2015). Similar to HB-EGF, loss of PTPN2 expression in $\mathrm{T}$ cells leads to enhanced Th17 differentiation, enhanced systemic inflammation and the transfer of naïve, PTPN-2 deficient CD4 T cells into Rag $^{-/}$mice to a rapid on-set of colitis (Spalinger et al., 2015). PTPN-2 is a pivotal regulator of EGFR activity (Stanoev et al., 2018) and several genetic studies revealed that loss-of-function variants of PTPN2 are linked to chronic inflammatory and autoimmune disorders (Doody et al., 2009). Thus, one way by which loss-of-function variants of PTPN2 may contribute to the development of autoimmune diseases could potentially be via a disrupted regulation of EGFR activity of CD4 T cells. SNPs in the promoter region of HB-EGF have been associated with Alzheimer's Disease (AD) (Jun et al., 2017) and it has been established that $A D$ is closely related to enhanced inflammation in the brain (Heppner et al., 2015). Therefore, it is tempting to speculate that altered HB-EGF expression by $\mathrm{T}$ cells might potentially be one factor contributing to $A D$ development.

Thus, taken together, while it is already well-established that EGFR expression by CD4 T cells is a critical regulator of their effector function (Minutti et al., 2017; Zaiss et al., 2013; Zeboudj et al., 2018), our data reveal yet another pathway by which the expression of the high-affinity EGFR ligand HB-EGF prevents the differentiation of Th-17 cells. As one of the few RTKs, the EGFR shows a "biased agonism" (Freed et al., 2017). This means that ligands of different affinity induce different signals downstream of the receptor (Freed et al., 2017). The highaffinity EGFR ligand HB-EGF induces a selective autophosphorylation of EGFR-Y1068 and thus the activation of the MAPK signalling pathway (Minutti et al., 2017), which we demonstrate here leads to elevated expression levels of IL-2 and STAT-5 signalling. In contrast, the low affinity EGFR ligand Amphiregulin induces the selective autophosphorylation of EGFR-Y992 (Minutti et al., 2017) and thus a sustained signalling via the Phospholipase C 
(PLC) signalling pathway (Minutti et al., 2019); in this way resembling the signalling induced by the IGFR (DiToro et al., 2020). Amphiregulin-induced, sustained PLC signalling induces then the "inside out" activation of integrins, such as integrin- $\alpha_{v}$ (Minutti et al., 2019), a process known to mediate the local activation of bio-active TGF $\beta$ and is critical for Treg-mediated immune suppression (Worthington et al., 2015). Thus, the activation of integrin- $\alpha_{v}$ on Tregs might be one mechanism by which the low-affinity EGFR ligand Amphiregulin enhances suppressive capacity of Tregs (Zaiss et al., 2013). Consequently, due to the biased agonism of the EGFR the local expression of EGFR ligands with different affinity for their receptor has the potential to influence the effector function of CD4 T cells and thus may regulate local immune responses, while the interruption of this signalling pathway may predispose for the development of autoimmune diseases. 


\section{MATERIALS AND METHODS}

\section{Breeding of Experimental Animals}

C57BI/6, Rag1 $1^{-/}$, CD45.1/.2 (Ly5 hets), CD4:cre $\times$Hbegf fl/fl and CD4:cre $\times$Egfr ${ }^{f / / f l}$ mice were bred and maintained on a C57BI/6 background at the University of Edinburgh, under specific pathogen free conditions. Mice were 6-12 weeks of age at the start of experiments and were housed in individually-ventilated cages. Mice were both age-matched and sex-matched, with both female and male mice being used. Experiments were performed in accordance with the United Kingdom Animals (Scientific Procedures) Act of 1986. All researchers were accredited for animal handling and experimentation by the UK Home Office. Experimentation at the University of Edinburgh was approved by the University of Edinburgh Animal Welfare and Ethical Review body and granted the UK Home Office. All research was carried out under the project license PPL70/8470. No individual data points were excluded.

\section{Primary Cell Isolation}

\section{Spleen and lymph nodes}

Mouse spleens and (mesenteric/inguinal) lymph nodes were homogenised by gentle processing through a $70 \mu \mathrm{M}$ cell strainer to form a single cell suspension. Splenocytes were subsequently treated with red blood cell lysis buffer (Sigma). Cells were counted using a haemocytometer and microscope (Zeiss). Staining and Cell Sorting detailed in "Flow Cytometry, Re-stimulation and FACS-sorting".

\section{Small Intestine}

Small intestinal intraepithelial lymphocytes (IELs) and lamina propria lymphocytes (LPL) were isolated as described before (Minutti et al., 2017). In brief, mice were sacrificed and small intestines were placed in ice-cold complete PBS. After removal of residual mesenteric fat tissue and Peyer's patches, intestines were cut roughly into $0.5-1 \mathrm{~cm}$ pieces, and washed thoroughly by vortexing in PBS. Tissue was placed into pre-digestion buffer (HBSS containing $10 \mathrm{mM}$ HEPES, 5mM EDTA, $1 \mathrm{mM}$ DTT and 5\% FCS) and incubated for 20 minutes at 37 degrees with frequent shaking. Tubes were vortexed intensely for $10 \mathrm{~s}$, and passed through $70 \mu \mathrm{M}$ cell strainers into $50 \mathrm{ml}$ falcon tube. The flow through contained the IEL population, and was stored on ice for further use. Tissue was transferred into fresh pre-warmed pre-digestion buffer, and incubation and straining was repeated as above. Tissues were then transferred into HBSS with $5 \%$ FCS for 10 minutes at 37 degrees with frequent shaking, vortexed, and passed through a cell strainer. All flow through containing IEL was collected and pooled together. Intestinal tissue was then transferred into pre-warmed digestion buffer (HBSS containing $10 \mathrm{mM}$ HEPES, $0.5 \mathrm{mg} / \mathrm{ml}$ Collagenase $\mathrm{D}, 0.5 \mathrm{mg} / \mathrm{ml}$ DNAse I and $5 \%$ FCS) and 
incubated at 37 degrees for 30 minutes with frequent shaking. Tissue was passed through a cell strainer and washed in FACS buffer (Dulbecco's phosphate buffered saline with $2 \%$ FCS) before centrifugation at $300 \mathrm{~g}$ for 5 minutes at 4 degrees. The cell pellet (containing LPL) was then resuspended in FACS buffer and stored on ice for further use. Staining detailed in "Flow Cytometry, Re-stimulation and FACS-sorting".

\section{Colon}

Colons were removed and flushed using PBS to remove faeces. Tissue was then digested as above for small intestine. Briefly, colons were cut up into $0.5-1 \mathrm{~cm}$ pieces, washed by vortexing in PBS, and placed into pre-digestion buffer at 37 degrees for the specific time mentioned above. Tissues were passed through cell strainers (this time not collecting the flow through), and this process was repeated again. Tissues were incubated in HBSS with $5 \%$ FCS as above, and finally digested in digestion buffer, before centrifugation at $300 \mathrm{~g}$ for 5 minutes at 4 degrees before resuspension of cell pellets in FACS buffer. Staining detailed in "Flow Cytometry, Re-stimulation and FACS-sorting".

\section{Flow Cytometry, Re-stimulation and FACS-sorting}

Single cell suspensions were prepared as previously described in "Primary Cell Isolation". Cells were incubated with Fc block (CD16/CD32) (BioLegend), and labelled with fluorescent conjugated antibodies against different cell surface antigens (see below). For detection of intracellular markers, cells were incubated at 37 degrees for 6 hours with $2 \mu \mathrm{g} / \mathrm{ml}$ anti-CD3 in the presence of $2 \mu \mathrm{M}$ monensin to re-stimulate cells and block protein transport, respectively. Alternatively, cells were re-stimulated by incubating with $50 \mathrm{ng} / \mathrm{ml}$ phorbol myristate acetate (PMA) and $500 \mathrm{ng} / \mathrm{ml}$ ionomycin at 37 degrees for 4 hours in the presence of monensin. Cells were washed and stained for surface markers as above, before subsequent fixation with $2 \%$ paraformaldehyde in Dulbecco's phosphate buffered saline for 20 minutes at room temperature, permeabilisation with Perm wash (BD Biosciences), and staining with antibodies against intracellular antigens. For detection of intranuclear antigens, cells were stained for surface markers, fixed and permeabilised using FoxP3 staining buffer set (eBioscience), and subsequently stained with antibodies against intranuclear antigens. For Flow Cytometry, Live/Dead (Life Technologies) was used to exclude dead cells from analysis, and samples were analysed using Becton-Dickinson BD SORP LSR II and FlowJo software v9 (Treestar Inc). For Cell Sorting, naïve cells (CD4 ${ }^{+}$CD25- CD45RB $\left.{ }^{\text {hi }}\right)$ were sorted using BD FACSAria IIU and again analysed using FlowJo software. 


\section{In vitro T cell differentiation}

Sorted naïve CD4 T cells (see "Flow Cytometry and FACS") were cultured in Iscoves Modified Dulbecco's Medium (IMDM) containing 10\% FCS, penicillin/streptomycin, L-Glutamine and $\beta$ mercaptoethanol (from now referred to as 'complete IMDM') at a density of $10^{6} / \mathrm{ml}$. For Th1 and iTreg differentiation, cells were cultured in plates coated with $1 \mu \mathrm{g} / \mathrm{ml}$ anti-CD3 and $2 \mu \mathrm{g} / \mathrm{ml}$ anti-CD28. For Th17 differentiation, cells were cultured in plates coated with $1 \mu \mathrm{g} / \mathrm{ml}$ anti-CD3 and $10 \mu \mathrm{g} / \mathrm{ml}$ anti-CD28. The following cytokines were added to generate each subset: Th1 $10 \mathrm{ng} / \mathrm{ml} \mathrm{IL-12}$ and $5 \mu \mathrm{g} / \mathrm{ml}$ anti-IL-4 (clone 11B11); iTreg $10 \mathrm{ng} / \mathrm{ml}$ TGF $\beta$ and $10 \mathrm{ng} / \mathrm{ml}$ IL-2; Th17 50ng/ml IL-6, 10ng/ml IL-1 $\beta, 10 \mathrm{ng} / \mathrm{ml} \mathrm{IL-23,} 1 \mathrm{ng} / \mathrm{ml}$ TGF $\beta$ and 300nM FICZ. After 48 hours, $5 \mathrm{ng} / \mathrm{ml} \mathrm{IL-2}$ was added to all wells for Th1 differentiation. Recombinant HB-EGF was added to cultures as specified $(0.01-100 \mathrm{ng} / \mathrm{ml})$. Cells were split $1: 2$ on day 2 after stimulation and analysed by Flow Cytometry on day 4-6.

\section{Cell Trace Violet proliferation}

Sorted naïve CD4 T cells were stained with $1 \mu \mathrm{l} / \mathrm{ml}$ CellTrace Violet Proliferation Kit (Thermofisher, Cat. C34571) in the dark for 20 minutes at room temperature. Five times the volume of complete IMDM was subsequently added for 5 minutes at room temperature before centrifugation. Cells were cultured at a density of $10^{6} / \mathrm{ml}$ in pre-warmed complete IMDM containing mouse T-activator anti-CD3/CD28 Dynabeads (Thermofisher) to give a final beadto-cell ratio of 1:1. After 24 hours, some cells were analysed for CellTrace Violet expression to generate a baseline peak. After 48 hours, $2 \mathrm{ng} / \mathrm{ml} \mathrm{IL-2}$ was added to cells. After 96 hours, all cells were analysed for CellTrace Violet expression.

\section{IL-2 ELISA}

Sorted naïve CD4 T cells were cultured in complete IMDM at a density of $10^{6} / \mathrm{ml}$ in the presence of mouse T-activator anti-CD3/CD28 Dynabeads (Thermofisher) at a bead-to-cell ratio of 1:1. After 24 hours, cells were centrifuged and supernatants stored at -20 degrees for further analysis by ELISA. IL-2 ELISA was performed using IL-2 Mouse Uncoated ELISA Kit (Invitrogen) following manufacturer's protocol.

\section{Anti-CD3 injection}

Mice were injected intraperitoneally with $50 \mu \mathrm{g}$ anti-CD3 antibody (clone 145-2C11) in PBS. After 48 hours, mice were sacrificed and spleens, mesenteric lymph nodes and small intestines harvested. Cells were isolated as specified in "Primary Cell Isolation" and restimulated/stained as detailed in "Flow Cytometry, Re-stimulation and FACS-sorting". 


\section{$\operatorname{Rag}^{-/-} \mathrm{T}$ cell transfer model and TGF $\beta$ blocking antibody addition}

Rag 1/- CD45.1 mice were injected intravenously with $4 \times 10^{5}$ FACS sorted naïve CD4 ${ }^{+} \mathrm{T}$ cells. Depending on the experiment, mice were either injected with wild type or HB-EGF-deficient cells, or a 1:1 mixture of wild type (CD45.1) and HB-EGF-deficient (CD45.2) cells. In specified experiments, Rag1// mice were injected with $5 \mathrm{mg} / \mathrm{kg}$ TGF $\beta$ blocking antibody (1D11) 3 times weekly for the first 3 weeks. Wasting disease was determined by weight loss compared to original weight, and mice culled when the group lost an average of $20 \%$ body weight. To assess cell proliferation and effector $\mathrm{CD}^{+} \mathrm{T}$ cell populations in $\operatorname{Rag} 1^{-/}$mice receiving a 1:1 mix of cells, mice were culled at weeks 1,2 and 3 post injection of naïve CD4 ${ }^{+} \mathrm{T}$ cells. Cells were isolated and stained from spleens, mesenteric lymph nodes and colons as specified in "Primary Cell Isolation" and "Flow Cytometry, Re-stimulation and FACS-sorting". Spleens, liver, kidney, pancreas, small intestines and colons were placed into $10 \%$ neutral-buffered Formalin solution overnight, before transfer into $70 \%$ ethanol solution for analysis by histology. Colons and small intestines were stained with heamatoxylin and eosin (H\&E).

\section{EAE}

Mice were anaesthetised using Isoflurane and immunised subcutaneously with $200 \mu \mathrm{g} \mathrm{MOG}_{35}$ 55 (MEVGWYRSPFSRVVHLYRNGK) emulsified in Complete Freund's Adjuvant (CFA) containing $500 \mu \mathrm{g} / \mathrm{ml}$ heat-killed Mycobacterium tuberculosis (H37RA), into both hind legs. Mice received 200ng pertussis toxin intraperitoneally on days 0 and 2 after induction. Clinical evaluation was performed using a 5-point scale: $\mathbf{0}$ no clinical signs; 1 flaccid tail; 2 impaired righting reflex and/or gait; $\mathbf{3}$ partial hind limb paralysis; $\mathbf{4}$ total hind limb paralysis; 5 total hind limb paralysis with partial fore limb paralysis. Mice were culled once they exceeded grade 3 , or upon $>20 \%$ weight loss or adverse signs such as substantial dyspnoea, weakness, dehydration or a hunched appearance.

\section{Human CRISPR}

Human CD4 T cells were MACS-sorted from PBMC and subsequently pre-activated with $\alpha$ CD3/CD28 Dynabeads (Thermofisher) at a bead-to-cell ratio of 1:1 for 48 hours. Next, dynabeads were removed and the CD4 T cells were rested for 24 hours. For CRISPR/Cas9 knockout $0.8 \times 10^{6}$ cells were mixed with $2.5 \mu \mathrm{l}$ crRNA/TracRNA complex (200uM), $1.67 \mu \mathrm{l}$ Cas9 nuclease 3NLs and $5.83 \mu$ l Buffer R (integrated DNA technologies, Coralville, US) and incubated at room temperature for $20 \mathrm{~min}$. This cell mix was transfected using the neon pipette station 1600 volts, $10 \mathrm{~ms}, 3$ pulses. After electroporation cells were transferred into 48-wells plate containing pre-warmed complete RPMI culture media and cultured for 24 hours before analysis of Th17 cell differentiation. Sequences for crRNA guides were as follows: Hbegf 
target

sequences

ACTGGCCACACCAAACAAGGAGG,

GACCAGCTGCTACCCCTAGGAGG and CTTCATGGTCCCGCACCGAGAGG; Egfr target sequences GCTGCCCCGGCCGTCCCGGAGGG, GAGGATGTTCAATAACTGTGAGG and GAAAACCTGCAGATCATCAGAGG.

\section{Statistical analysis}

Statistical analysis was performed using Prism (GraphPad Software). All data were analysed using the Student's $t$ test. P-values $<0.05$ were considered statistically significant.

\section{ACKNOWLEDGEMENTS}

We thank N. Logan and the other members of the Zamoyska Lab for all their help and excellent technical assistance; and the vivarium support staff for excellent animal husbandry. D.M.Z. was supported by the Medical Research Council, grant MR/M011755/1. R.Z. has been supported by a Wellcome Trust Investigator Award (WT205014/Z/16/Z) and F.M. by an EastBio BBSRC PhD fellowship.

\section{AUTHOR CONTRIBUTIONS}

F.M. designed and performed experiments, analysed and interpreted data, and wrote the manuscript. K.P., A.M., R.C.S, L.W.P., L.N., J.Y. and D.H. performed experiments. D.W. provided expertise in CRISPR/Cas9 experimental design. S.H. produced the TGF $\beta$ blocking antibodies. A.G. stained sections and provided expertise in histology. M.W. provided expertise in Flow Cytometry and FACS, and edited the manuscript. R.Z. and J.V.L. contributed tools, provided expertise, and edited the manuscript. D.M.Z. designed the research, interpreted data and wrote the manuscript. 


\section{REFERENCES}

Annunziato, F., Cosmi, L., Liotta, F., Maggi, E., and Romagnani, S. (2009). Type 17 T helper cells-origins, features and possible roles in rheumatic disease. Nat Rev Rheumatol 5, 325331.

Beier, U.H., Wang, L., Han, R., Akimova, T., Liu, Y., and Hancock, W.W. (2012). Histone deacetylases 6 and 9 and sirtuin-1 control Foxp3+ regulatory T cell function through shared and isoform-specific mechanisms. Sci Signal 5, ra45.

Blotnick, S., Peoples, G.E., Freeman, M.R., Eberlein, T.J., and Klagsbrun, M. (1994). T lymphocytes synthesize and export heparin-binding epidermal growth factor-like growth factor and basic fibroblast growth factor, mitogens for vascular cells and fibroblasts: differential production and release by CD4+ and CD8+ T cells. Proc Natl Acad Sci U S A 91, 2890-2894.

Bourgeois, C., Kassiotis, G., and Stockinger, B. (2005). A major role for memory CD4 T cells in the control of lymphopenia-induced proliferation of naive CD4 T cells. J Immunol 174, 53165323.

Conti, H.R., Shen, F., Nayyar, N., Stocum, E., Sun, J.N., Lindemann, M.J., Ho, A.W., Hai, J.H., Yu, J.J., Jung, J.W., et al. (2009). Th17 cells and IL-17 receptor signaling are essential for mucosal host defense against oral candidiasis. J Exp Med 206, 299-311.

DiToro, D., Harbour, S.N., Bando, J.K., Benavides, G., Witte, S., Laufer, V.A., Moseley, C., Singer, J.R., Frey, B., Turner, H., et al. (2020). Insulin-Like Growth Factors Are Key Regulators of T Helper 17 Regulatory T Cell Balance in Autoimmunity. Immunity 52, 650-667 e610.

Doody, K.M., Bourdeau, A., and Tremblay, M.L. (2009). T-cell protein tyrosine phosphatase is a key regulator in immune cell signaling: lessons from the knockout mouse model and implications in human disease. Immunol Rev 228, 325-341.

Else, K.J., Finkelman, F.D., Maliszewski, C.R., and Grencis, R.K. (1994). Cytokine-mediated regulation of chronic intestinal helminth infection. J Exp Med 179, 347-351.

Esplugues, E., Huber, S., Gagliani, N., Hauser, A.E., Town, T., Wan, Y.Y., O'Connor, W., Jr., Rongvaux, A., Van Rooijen, N., Haberman, A.M., et al. (2011). Control of TH17 cells occurs in the small intestine. Nature $475,514-518$. 
Freed, D.M., Bessman, N.J., Kiyatkin, A., Salazar-Cavazos, E., Byrne, P.O., Moore, J.O., Valley, C.C., Ferguson, K.M., Leahy, D.J., Lidke, D.S., and Lemmon, M.A. (2017). EGFR Ligands Differentially Stabilize Receptor Dimers to Specify Signaling Kinetics. Cell 171, 683695 e618.

Harbour, S.N., Maynard, C.L., Zindl, C.L., Schoeb, T.R., and Weaver, C.T. (2015). Th17 cells give rise to Th1 cells that are required for the pathogenesis of colitis. Proc Natl Acad Sci U S A 112, 7061-7066.

Hardbower, D.M., Singh, K., Asim, M., Verriere, T.G., Olivares-Villagomez, D., Barry, D.P., Allaman, M.M., Washington, M.K., Peek, R.M., Jr., Piazuelo, M.B., and Wilson, K.T. (2016). EGFR regulates macrophage activation and function in bacterial infection. J Clin Invest 126, 3296-3312.

Heo, J., Kim, J.G., Kim, S., and Kang, H. (2018). Stat5 phosphorylation is responsible for the excessive potency of HB-EGF. J Cell Biochem 119, 5297-5307.

Heppner, F.L., Ransohoff, R.M., and Becher, B. (2015). Immune attack: the role of inflammation in Alzheimer disease. Nat Rev Neurosci 16, 358-372.

Hirota, K., Duarte, J.H., Veldhoen, M., Hornsby, E., Li, Y., Cua, D.J., Ahlfors, H., Wilhelm, C., Tolaini, M., Menzel, U., et al. (2011). Fate mapping of IL-17-producing T cells in inflammatory responses. Nat Immunol 12, 255-263.

Ivanov, II, McKenzie, B.S., Zhou, L., Tadokoro, C.E., Lepelley, A., Lafaille, J.J., Cua, D.J., and Littman, D.R. (2006). The orphan nuclear receptor RORgammat directs the differentiation program of proinflammatory IL-17+ T helper cells. Cell 126, 1121-1133.

Jun, G.R., Chung, J., Mez, J., Barber, R., Beecham, G.W., Bennett, D.A., Buxbaum, J.D., Byrd, G.S., Carrasquillo, M.M., Crane, P.K., et al. (2017). Transethnic genome-wide scan identifies novel Alzheimer's disease loci. Alzheimers Dement 13, 727-738.

Lanaya, H., Natarajan, A., Komposch, K., Li, L., Amberg, N., Chen, L., Wculek, S.K., Hammer, M., Zenz, R., Peck-Radosavljevic, M., et al. (2014). EGFR has a tumour-promoting role in liver macrophages during hepatocellular carcinoma formation. Nat Cell Biol 16, 972-977. 
Laurence, A., Tato, C.M., Davidson, T.S., Kanno, Y., Chen, Z., Yao, Z., Blank, R.B., Meylan, F., Siegel, R., Hennighausen, L., et al. (2007). Interleukin-2 signaling via STAT5 constrains T helper 17 cell generation. Immunity 26, 371-381.

Lee, Y.K., Turner, H., Maynard, C.L., Oliver, J.R., Chen, D., Elson, C.O., and Weaver, C.T. (2009). Late developmental plasticity in the T helper 17 lineage. Immunity 30, 92-107.

Liao, W., Schones, D.E., Oh, J., Cui, Y., Cui, K., Roh, T.Y., Zhao, K., and Leonard, W.J. (2008). Priming for T helper type 2 differentiation by interleukin 2-mediated induction of interleukin 4 receptor alpha-chain expression. Nat Immunol 9, 1288-1296.

Mahtouk, K., Hose, D., Reme, T., De Vos, J., Jourdan, M., Moreaux, J., Fiol, G., Raab, M., Jourdan, E., Grau, V., et al. (2005). Expression of EGF-family receptors and amphiregulin in multiple myeloma. Amphiregulin is a growth factor for myeloma cells. Oncogene 24, 35123524.

Minutti, C.M., Drube, S., Blair, N., Schwartz, C., McCrae, J.C., McKenzie, A.N., Kamradt, T., Mokry, M., Coffer, P.J., Sibilia, M., et al. (2017). Epidermal Growth Factor Receptor Expression Licenses Type-2 Helper T Cells to Function in a T Cell Receptor-Independent Fashion. Immunity 47, 710-722 e716.

Minutti, C.M., Modak, R.V., Macdonald, F., Li, F., Smyth, D.J., Dorward, D.A., Blair, N., Husovsky, C., Muir, A., Giampazolias, E., et al. (2019). A Macrophage-Pericyte Axis Directs Tissue Restoration via Amphiregulin-Induced Transforming Growth Factor Beta Activation. Immunity 50, 645-654 e646.

Modlin, R.L. (1994). Th1-Th2 paradigm: insights from leprosy. J Invest Dermatol 102, 828832.

Powrie, F., Correa-Oliveira, R., Mauze, S., and Coffman, R.L. (1994). Regulatory interactions between CD45RBhigh and CD45RBlow CD4+ T cells are important for the balance between protective and pathogenic cell-mediated immunity. J Exp Med 179, 589-600.

Sibilia, M., Kroismayr, R., Lichtenberger, B.M., Natarajan, A., Hecking, M., and Holcmann, M. (2007). The epidermal growth factor receptor: from development to tumorigenesis. Differentiation $75,770-787$. 
Spalinger, M.R., Kasper, S., Chassard, C., Raselli, T., Frey-Wagner, I., Gottier, C., Lang, S., Atrott, K., Vavricka, S.R., Mair, F., et al. (2015). PTPN2 controls differentiation of CD4(+) T cells and limits intestinal inflammation and intestinal dysbiosis. Mucosal Immunol 8, 918-929.

Stanoev, A., Mhamane, A., Schuermann, K.C., Grecco, H.E., Stallaert, W., Baumdick, M., Bruggemann, Y., Joshi, M.S., Roda-Navarro, P., Fengler, S., et al. (2018). Interdependence between EGFR and Phosphatases Spatially Established by Vesicular Dynamics Generates a Growth Factor Sensing and Responding Network. Cell Syst 7, 295-309 e211.

Tuettenberg, A., Hahn, S.A., Mazur, J., Gerhold-Ay, A., Scholma, J., Marg, I., Ulges, A., Satoh, K., Bopp, T., Joore, J., and Jonuleit, H. (2016). Kinome Profiling of Regulatory T Cells: A Closer Look into a Complex Intracellular Network. PLoS One 11, e0149193.

Vantourout, P., Willcox, C., Turner, A., Swanson, C.M., Haque, Y., Sobolev, O., Grigoriadis, A., Tutt, A., and Hayday, A. (2014). Immunological visibility: posttranscriptional regulation of human NKG2D ligands by the EGF receptor pathway. Sci Transl Med 6, 231 ra249.

Worthington, J.J., Kelly, A., Smedley, C., Bauche, D., Campbell, S., Marie, J.C., and Travis, M.A. (2015). Integrin alphavbeta8-Mediated TGF-beta Activation by Effector Regulatory T Cells Is Essential for Suppression of T-Cell-Mediated Inflammation. Immunity 42, 903-915.

Yang, X.P., Ghoreschi, K., Steward-Tharp, S.M., Rodriguez-Canales, J., Zhu, J., Grainger, J.R., Hirahara, K., Sun, H.W., Wei, L., Vahedi, G., et al. (2011). Opposing regulation of the locus encoding IL-17 through direct, reciprocal actions of STAT3 and STAT5. Nat Immunol $12,247-254$.

Zaiss, D.M., van Loosdregt, J., Gorlani, A., Bekker, C.P., Grone, A., Sibilia, M., van Bergen en Henegouwen, P.M., Roovers, R.C., Coffer, P.J., and Sijts, A.J. (2013). Amphiregulin enhances regulatory $\mathrm{T}$ cell-suppressive function via the epidermal growth factor receptor. Immunity 38, 275-284.

Zeboudj, L., Maitre, M., Guyonnet, L., Laurans, L., Joffre, J., Lemarie, J., Bourcier, S., NourEldine, W., Guerin, C., Friard, J., et al. (2018). Selective EGF-Receptor Inhibition in CD4(+) T Cells Induces Anergy and Limits Atherosclerosis. J Am Coll Cardiol 71, 160-172. 


\section{Figures:}

A

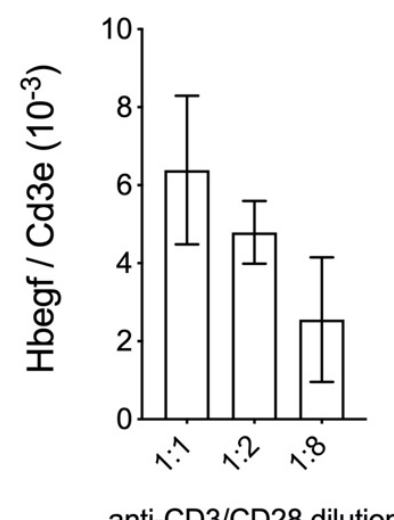

B

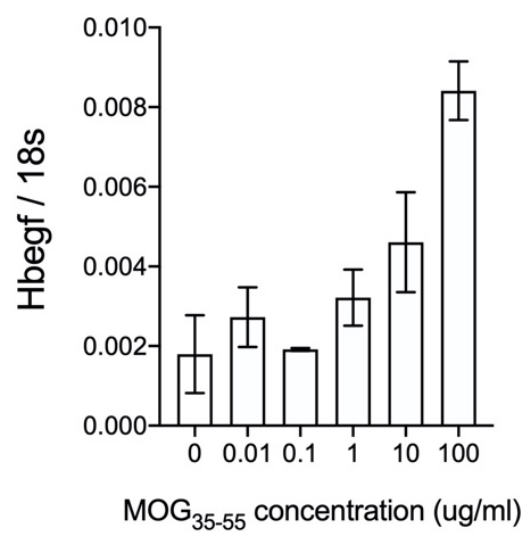

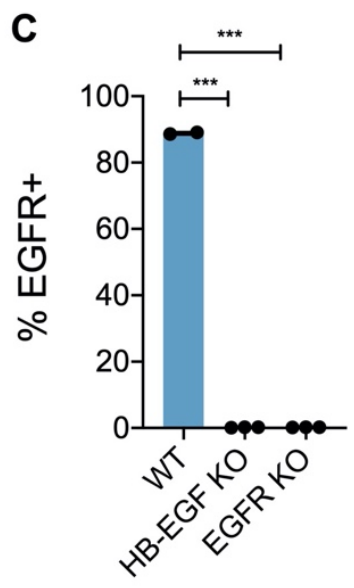

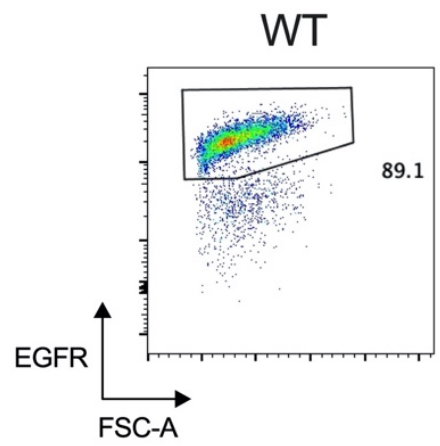

HB-EGF KO

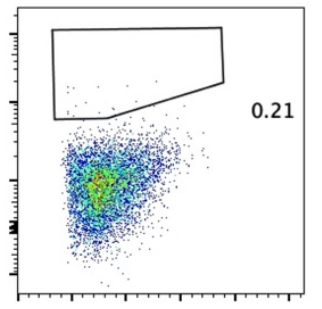

EGFR KO

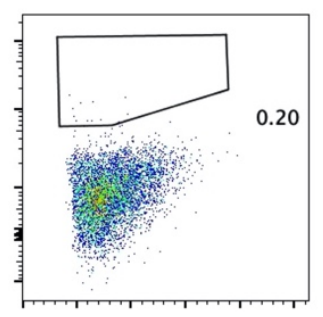

Figure 1: CD4+ T cells express EGFR and HB-EGF upon activation. (A) Naïve CD4+ T cells were activated with decreasing concentrations of a-CD3/a-CD28 stimulatory beads in vitro. Quantification of Hbegf mRNA expression was performed following o/n stimulation. (B) Naïve 2D2 TCR transgenic CD4+ T cells were activated in vitro with BM-DCs pulsed with increasing concentrations of TCR specific MOG peptide. Quantification of $H b e g f$ mRNA expression is shown following o/n stimulation. (C) Naïve CD4+ T cells from WT, CD4 ${ }^{\triangle H B-E G F}$ and CD4 ${ }^{\triangle E G F R}$ mice were activated in vitro with $\alpha-C D 3 / \alpha-C D 28$-coated stimulator beads for 24 hours. Cells were stained for CD4 and EGFR, and analysed by flow cytometry. Surface staining and graphs show quantification of EGFR expression. Error bars show mean \pm SEM. $n=2-3$ in each group. 
A
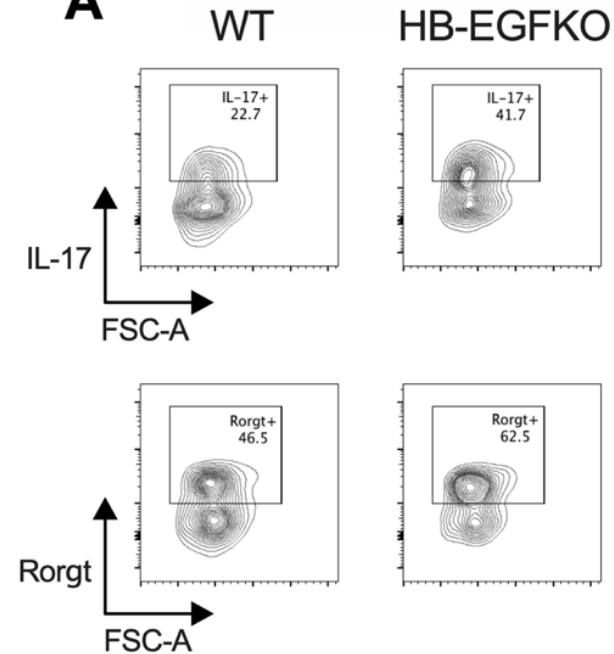

$\underset{\text { FSC-A }}{\longrightarrow}$

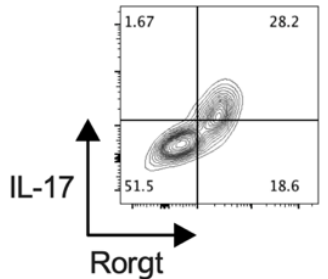

HB-EGFKO

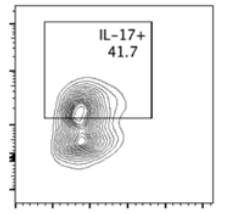

B

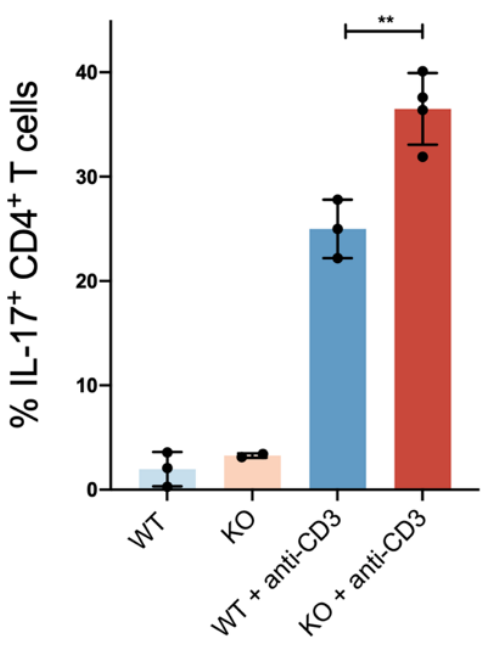

C

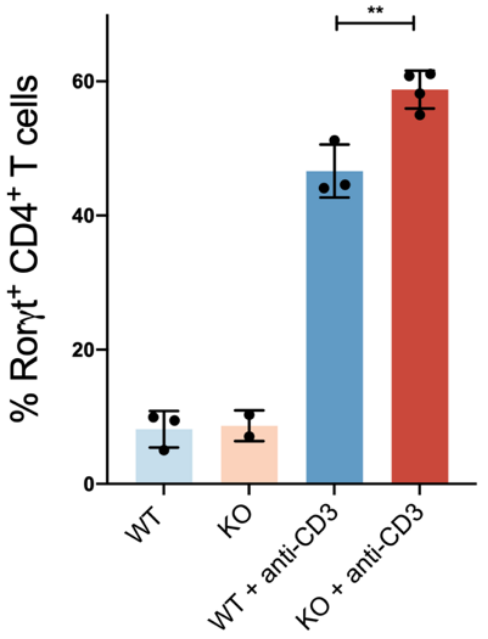

Figure 2: Enhanced in vivo expansion of the Th17 population in mice with HB-EGF-deficient T cells using a model of $\alpha$-CD3-induced T cell activation. (A-C) WT and CD4 ${ }^{\triangle H B-E G F}$ mice were injected intraperitoneally with $\alpha-C D 3$ antibody, and culled 48 hours later. Intraepithelial lymphocytes (IEL) were isolated from small intestines. Cells were stained for CD4, CD3, IL-17 and Ror $\gamma$ t before analysis by flow cytometry. (A) Representative FACS plots and quantified data is shown for IL-17 $7^{+}$cells (top), Ror $\gamma \mathrm{t}^{+} \mathrm{T}$ cells (middle) and $\mathrm{IL}-17^{+}$Ror $\gamma \mathrm{t}^{+} \mathrm{T}$ cells (bottom) as a proportion of $\mathrm{CD} 4^{+} \mathrm{CD}^{+}$lymphocytes. $(\mathrm{B}+\mathrm{C})$ Quantified data seen in $(\mathrm{A})$ for $\mathrm{IL}-17^{+}$cells $(\mathrm{B})$ or Roryt $\mathrm{t}^{+} \mathrm{T}$ cells (C) as a proportion of $\mathrm{CD}^{+} \mathrm{CD}^{+}$lymphocytes. Error bars show mean \pm SEM. $n=2-5$ in each group. Student's $t$ tests were used to assess significance. 
A

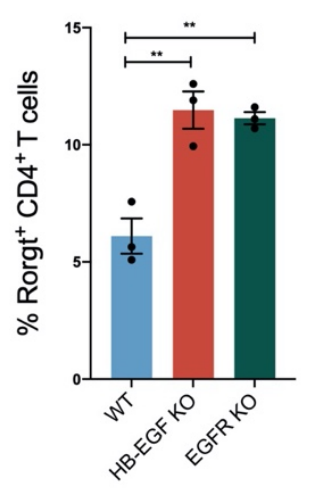

B

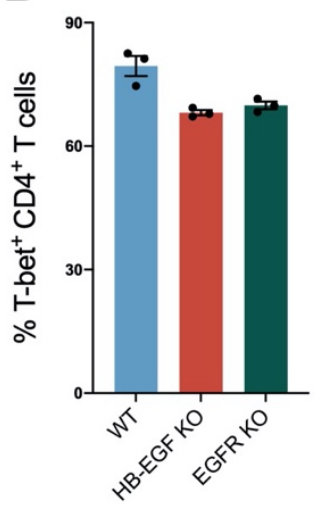

C

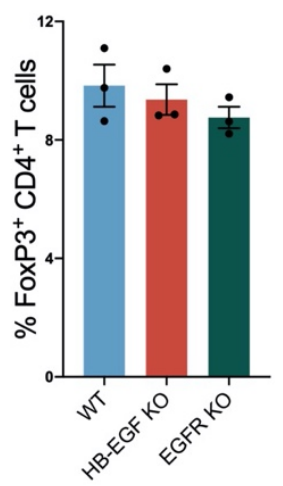

D

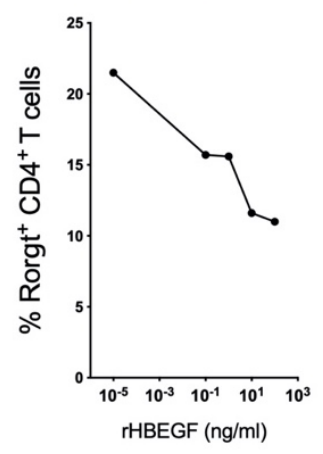

EGFR KO

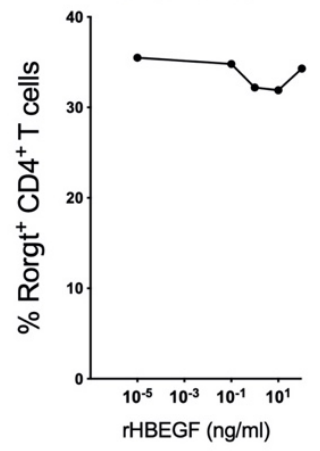

Figure 3: Enhanced in vitro Th17 cell differentiation of HB-EGF-deficient CD4+ T cells.

Naïve CD4 ${ }^{+} \mathrm{T}$ cells $\left(\mathrm{CD} 4^{+} \mathrm{CD} 45 \mathrm{RB}^{+} \mathrm{CD} 25^{-}\right)$were FACS sorted from spleens of WT, CD4 ${ }^{\Delta \mathrm{HB}-\mathrm{EGF}}$ $\mathrm{CD} 4^{\triangle \mathrm{EGFR}}$ mice and activated in vitro using $\alpha-\mathrm{CD} 3 / \alpha-C D 28$ antibodies coated beads. $(\mathrm{A})$ Cells were cultured in IL$1 \beta$, IL-6, IL-23, TGF $\beta$ and FICZ for 5 days to polarise towards a Th17 phenotype. Cells were stained for CD4, CD3 and Th17 master transcription factor ROR $\gamma$ t before analysis by flow cytometry. Dead cells were excluded from analysis by staining cells with a live/dead dye. Quantification of Ror $\gamma \mathrm{t}^{+}$cells as a proportion of $\mathrm{CD}^{+} \mathrm{CD}^{+}$ lymphocytes. $(B+C)$ Cells were polarised towards a Th1 (IL-12 and $\alpha-I L-4)(B)$ or iTreg (TGF $\beta$ and IL-2) (C) phenotype. Cells were stained for CD4, CD3 and master transcription factors T-bet (Th1) or FoxP3 (iTreg) before analysis by flow cytometry. Graphs show quantification of $\mathrm{T}^{- \text {bet }^{+}}(\mathrm{B})$ or FoxP3 ${ }^{+}(\mathrm{C})$ cells as a proportion of $\mathrm{CD} 4^{+}$ $\mathrm{CD}^{+}$lymphocytes. (D) Recombinant HB-EGF was added to the culture media of naïve CD4+ $\mathrm{T}$ cells before polarisation towards a Th17 phenotype as in (A). Graphs show quantification of Roryt ${ }^{+}$cells as a proportion of CD4 ${ }^{+}$ $\mathrm{CD}^{+}$lymphocytes upon addition of increasing concentrations of rHB-EGF from CD4 ${ }^{\triangle H B-E G F}$ (left) or CD4 ${ }^{\triangle E G F R}$ (right) mice. Error bars show mean \pm SEM. $n=3$ in each group. Student's $t$ tests were used to assess significance. 
A

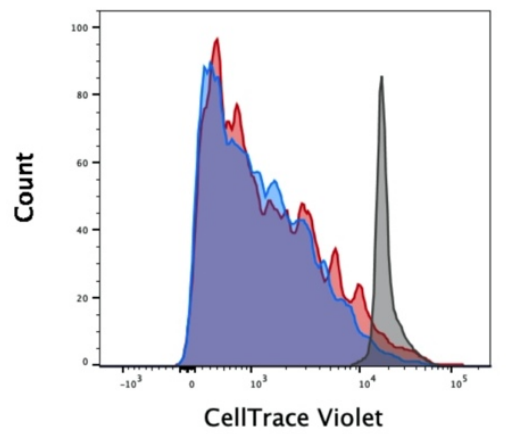

B

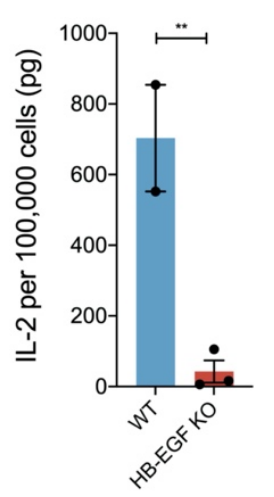

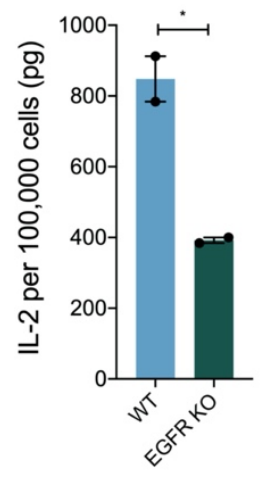

C

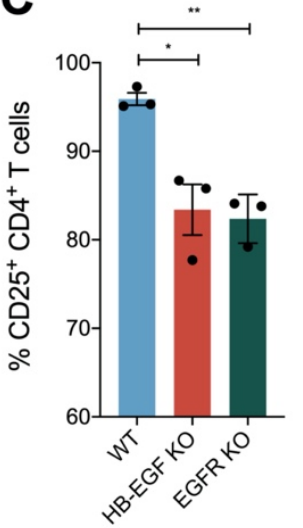

D

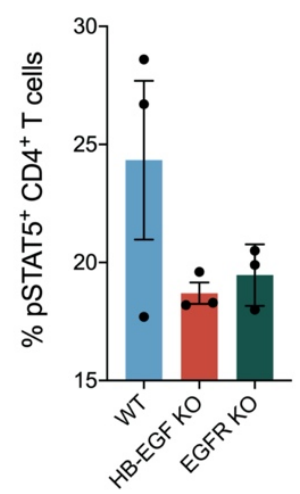

E

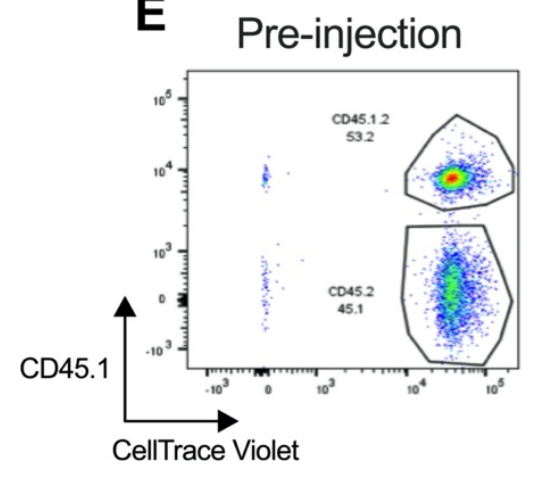

D5 post-injection

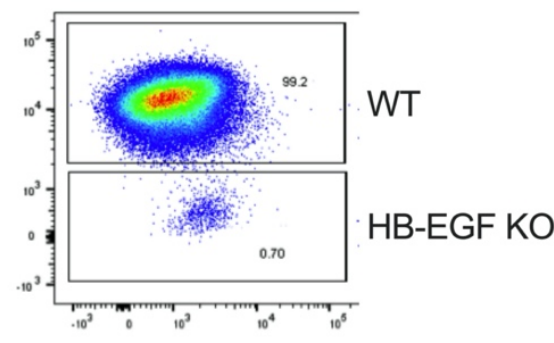

Figure 4: HB-EGF-deficient CD4 T cells produce less IL-2 upon activation and show inferior recovery compared to wt cells after transfer into Rag1/- mice. (A) Sorted naïve CD4 ${ }^{+} \mathrm{T}$ cells from spleens of wt and CD4 ${ }^{\triangle \mathrm{HB}-\mathrm{EGF}}$ mice were stained with CellTrace Violet Cell Proliferation Kit and activated in vitro in the presence of recombinant IL-2 for 4 days. FACS plot shows unstimulated control cells after 24 hours in culture (grey), along with cells from WT (blue) and CD4 ${ }^{\triangle \mathrm{HB}-\mathrm{EGF}}$ (red) mice. Each peak represents distinct proliferation. (B-D) Naïve CD4 ${ }^{+} \mathrm{T}$ cells from WT, CD4 ${ }^{\triangle H B-E G F}$, and CD4 ${ }^{\triangle E G F R}$ mice were activated in vitro with $\alpha$-CD3/ $\alpha$-CD28-coated stimulator beads for 24-48 hours. (B) Supernatants were harvested, and ELISA was performed to determine IL-2 concentration per 100,000 cells. (C+D) Cells were stained for CD4, CD3, CD25 and intranuclearly for pSTAT5, and analysed by flow cytometry. Surface staining and graphs show quantification of $\mathrm{CD}_{2} 5^{+}(\mathrm{C})$ or $\mathrm{pSTAT5}^{+}(\mathrm{D})$ cells as a proportion of $\mathrm{CD}^{+} \mathrm{CD}^{+}$lymphocytes. (E) Rag1/- mice (CD45.1) were intravenously injected with a 1:1 mixture of WT (CD45.1/CD45.2) and HB-EGF-deficient (CD45.2) naïve CD4 T cells. FACS plot of WT (CD45.1 ${ }^{+}$) and HB-EGFdeficient (CD45.1 $1^{-}$) cell mixture post injection (left) or 5 days after injection into Rag $1^{-/-}$mice against CellTrace Violet staining (right). All experiments were performed at least twice with similar results. Error bars show mean \pm SEM. $n=2-3$ in each group. Student's t tests were used to assess significance. 
bioRxiv preprint doi: https://doi.org/10.1101/2021.02.09.430418; this version posted February 10, 2021. The copyright holder for this preprint (which was not certified by peer review) is the author/funder. All rights reserved. No reuse allowed without permission.

A
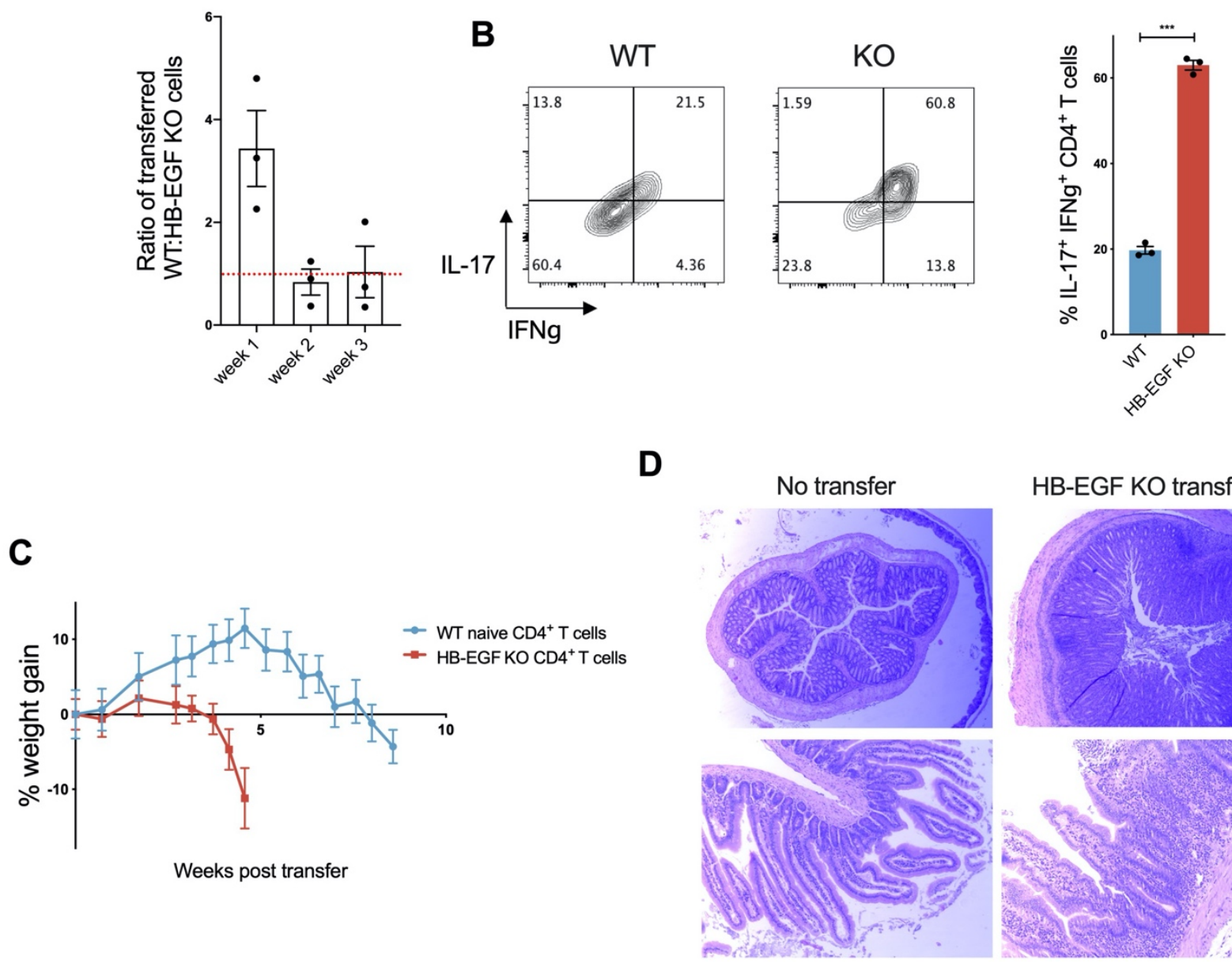

HB-EGF KO transfer

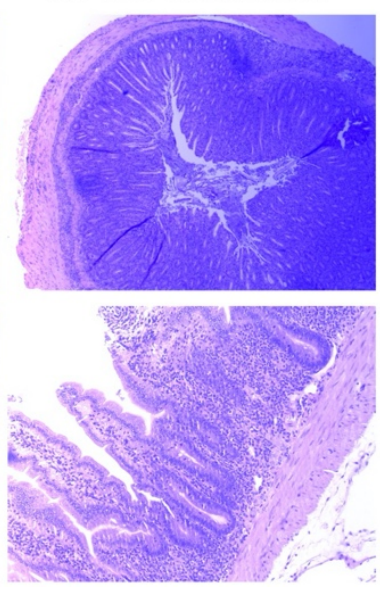

Colon

Figure 5: HB-EGF-deficient CD4 T cells show enhanced Th17 differentiation and cause early onset of wasting disease. (A-B) Rag1/- mice (CD45.1) were intravenously injected with a 1:1 mixture of WT (CD45.1/.2) and HB-EGF-deficient (CD45.2) naïve CD4 T cells. (A) Ratio of WT (CD45.1) to HB-EGF-deficient (CD45.2) CD4 $\mathrm{T}$ cells in recipient Rag1/- mice at different time points post transfer. (B) Mice were culled at week 1 post transfer, and splenocytes stimulated ex vivo with PMA and ionomycin for 4 hours. Cells were subsequently stained for CD45.1, CD45.2, CD4, CD3 plus intracellularly for IL-17 and IFN $\gamma$. FACS plots and quantified data show percentage

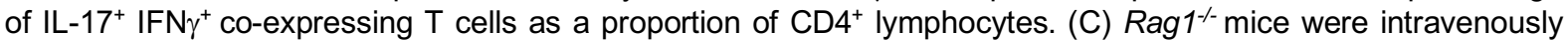
injected with either 500,000 WT (blue) or HB-EGF-deficient (red) naïve CD4 T cells. Mice were weighed frequently for onset of wasting disease. Graph shows percentage weight gain of mice compared to their original body weight post injection. (D) Histology slides of colon (x20 magnification) or small intestine (x100) from either C57BI/6 wt mice or Rag1\%-mice injected with HB-EGF-deficient naïve CD4 T cells (taken 3 weeks post-transfer) stained with $\mathrm{H} \& E$. Error bars show mean \pm SEM. $n=3-5$ in each group. Student's $t$ tests were used to assess significance. 
A

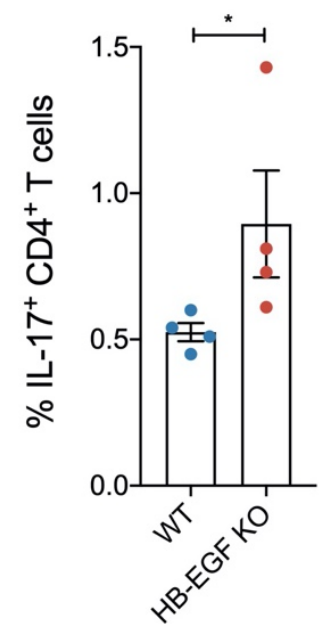

B

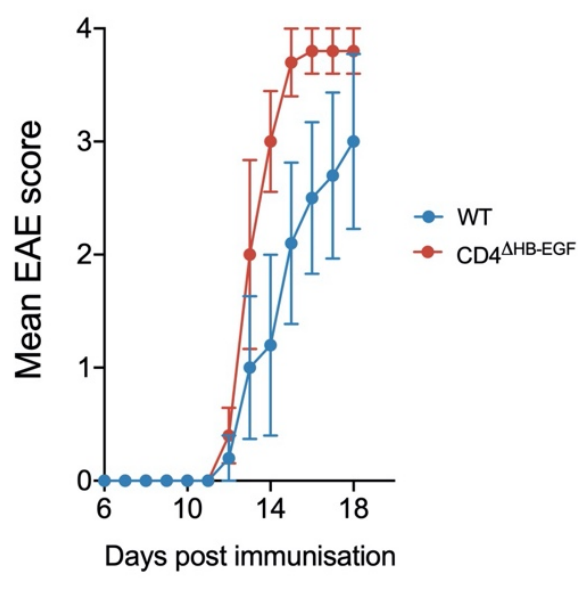

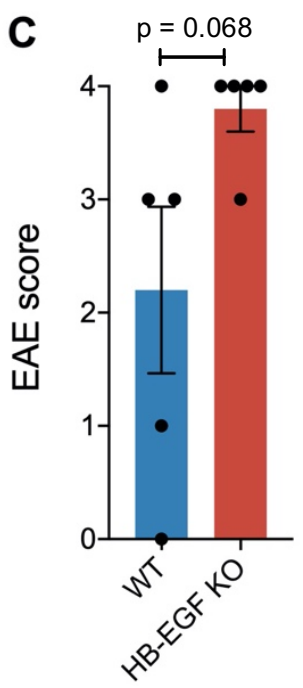

Figure 6: HB-EGF-deficient CD4 T cells show enhanced Th17 differentiation after immunisation with MOG $_{35}$ 55 peptide, early onset and more severe symptoms of EAE. (C) Mice were immunised with CFA/MOG ${ }_{35-55}$ subcutaneously into the base of the tail and culled after 7 days. Splenocytes were re-stimulated ex vivo with $\mathrm{MOG}_{35}$ ${ }_{55}$ peptide CFA/MOG $35-55$ for 6 hours. Cells were subsequently stained for CD4, CD3 plus intracellularly for IL-17. Quantified data show percentage of $\mathrm{IL}-17^{+} \mathrm{T}$ cells as a proportion of $\mathrm{CD} 4^{+} \mathrm{CD} 3+$ lymphocytes. $(\mathrm{B}+\mathrm{C}) \mathrm{EAE}$ was induced in WT and CD4 ${ }^{\triangle \mathrm{HB}-\mathrm{EGF}}$ mice by subcutaneous injection of CFA/MOG 35 -55 into the base of the tail followed by intraperitoneal injection of pertussis toxin. (A) mean EAE scores and (B) EAE scores on day 15 are shown. Error bars show mean $\pm S D$. $n=4-5$ in each group. Student's $t$ tests were used to assess significance. 